\title{
The Clinical and Pathological Characteristics and Survival of Patients With Advanced Ovarian Cancer
}

\author{
Miroslav Popović,1, 2 Tanja Milić-Radić,, 2 Arnela Cerić-Banićević1, 2
}

\begin{abstract}
Introduction: Ovarian cancer has the highest mortality rate of all gynaecologic malignancies. The aim of this study was the evaluation of the clinical pathological characteristics and survival analysis of primarily operated patients with advanced stages of malignant epithelial ovarian tumour.

Methods: The research was conducted as a cohort study with 59 patients with FIGO stage III and IV, which were primarily operated between 1 January 2008 and 31 December 2010 (three years). Age, comorbidities, BMI, presence of ascites, the level of the marker CA-125, histopathology and FIGO stage were analysed. The survival rate was estimated at the level of 1,3 and 5 years.

Results: The median age was 53 years (range 29-86). The most common histopathological type was serous (66.1\%) and the most common FIGO stage was 3a (49.2\%). Optimal cytoreduction was performed in $35.5 \%$ of patients, $84.7 \%$ of patients survived for one year, $44.1 \%$ three years and $37.3 \%$ for five years. The median survival was 26.25 months (range 0 -91). Chi-square test showed significant difference between the number of months of survival and: the value of CA$125(\mathrm{t}=2.004, \mathrm{p}=0.050)$, cytoreduction $(\mathrm{p}<0.001)$ and FIGO stage $(\mathrm{p}<0.01)$. Conclusion: According to the results of this study, optimal cytoreduction and FIGO stage significantly influence survival $(\mathrm{p}<0.001)$. Optimal cytoreduction $(<2 \mathrm{~cm}$ of residual disease) had the highest prognostic value for survival. A total five-year survival in this study was $37.3 \%$.
\end{abstract}

Key words: Ovarian cancer; Radical surgery; Survival rate; Clinical features; Pathological features.
(1) Clinic of Gynaecology and Obstetrics, University Clinical Centre of the Republic of Srpska, Banja Luka, the Republic of Srpska, Bosnia and Herzegovina.

(2) Faculty of Medicine, University of Banja Luka, Banja Luka, the Republic of Srpska, Bosnia and Herzegovina.

\section{Correspondence:}

MIROSLAV D POPOVIĆ

E: drpopovic.gin1@gmail.com

T: +38765188 888

F: +38751342 204

\section{ARTICLE INFO}

Received: 10 September 2021

Revision received: 27 September 2021 Accepted: 28 September 2021

\section{Introduction}

Ovarian cancer makes $5 \%$ of all malignant tumours in women and has the highest mortality rate of all gynaecological malignancies. ${ }^{1}$ Ovarian cancer in the early stages of the disease is characterised by non-specific symptomatology which can easily be misinterpreted. ${ }^{2}$ Therefore, the disease is, in 60-70\% of cases, detected in advanced stages, which partly explains the high mortality. ${ }^{3}$

The aetiology of ovarian cancer is multifactorial. A number of factors increase the risk of ovarian cancer: a family history of ovarian cancer, previ- ous breast or endometrium cancer, lower parity or infertility, late menopause, age, genetic background, obesity and smoking, and exposure to chemical and biological agents from the environment. ${ }^{4,5}$ Marker, cancer antigen 125 (CA-125) is elevated in about $80 \%$ of patients with advanced disease stadiums. However, it is a non-specific marker which can be elevated in some benign conditions as well. ${ }^{6}$ The definitive diagnosis is based on histopathologic examination of tumour tissue after surgery (laparoscopy or laparotomy).

Copyright $\odot 2021$ Popović et al. This is an open access article distributed under the Creative Commons Attribution License (CC BY), which permits unrestricted use, distribution, and reproduction in any medium, provided the original work is properly cited. This article should be cited as follows: Popović M, Milić-Radić T, Cerić-Banićević A. The clinical and pathological characteristics and survival of patients with advanced ovarian cancer. Scr Med 2021 Sep;52(3):205-10. 
The standard surgical treatment of ovarian cancer involves a maximum reduction of the tumour mass, ie a hysterectomy with bilateral adnexectomy and omentectomy, and in some cases appendectomy and pelvic and/or para-aortic lymphadenectomy are done. ${ }^{7}$ In advanced stages of ovarian cancer cytoreductive surgery with the aim of a greater reduction of tumour mass is done, due to better effect of chemotherapy. ${ }^{8,9}$

The two most important prognostic factors for further postoperative course and outcome of disease are the stage of tumour disease at the moment of diagnosis (FIGO stage) and the volume of residual tumour tissue. ${ }^{10}$ Vergote and colleagues have shown that the mass of residual tumour expressed in grams and the age of the patient are the only two independent prognostic factors. ${ }^{11}$ Although the prognosis of patients with advanced ovarian cancer has improved in recent decades, the long-term survival remains low and is, despite all therapeutic measures, less than 50 $\%$ for 5 years overall. ${ }^{12}$ Therefore, there is a tendency to develop more effective therapeutic procedures, especially for patients whose tumours cannot be treated by initial optimal cytoreduction. ${ }^{13} \mathrm{~A}$ significant issue in the treatment of advanced ovarian cancer concerns the assessment of surgical cytoreduction, which has not proved reliable even by visual inspection methods, serum biomarkers, and even with the help of molecular biology. Although there are still few studies on the role of laparoscopy in valuating resectability in advanced ovarian cancer, it proved to be a promising approach. ${ }^{14}$

The aim of this study was to evaluate the clinical pathological characteristics and survival analysis of primarily operated patients with advanced stages of malignant epithelial ovarian tumours at the Clinic of Gynaecology and Obstetrics, University Clinical Centre of the Republic of Srpska, Banja Luka, Bosnia and Herzegovina (Clinic).

\section{Methods}

The research was conducted as a cohort study in the Clinic. It included 59 patients who were primarily radically operated in the period from 1 January 2008 to 31 December 2010 (three years), in which the changes to adnexa were preopera- tively diagnosed and malignant epithelial ovarian tumour of the third and fourth (FIGO III and IV) stage was postoperatively histopathologically confirmed. Prospective part of the study observed the five-year survival of all operated patients and the state of their vital status until 31 December 2015. The basic epidemiological data, personal, family, gynaecological history and the results of laboratory tests [blood count, level of tumour markers (CA 125, HE 4, Roma index)] were taken from all the patients from medical archives of the Clinic for Gynaecology and Obstetrics of University Clinical Centre of Banja Luka.

In patients in whom it was preoperatively estimated that the tumour was resectable, the disease stage was determined by laparotomy and radical surgery was made and in accordance with current protocols. The decision as to whether the patient will be primarily operated or will go to neoadjuvant chemotherapy was based on a clinical review, general condition, age, performance status and results of the CT scan. In all operable patients, and depending on the stage of the disease, the total hysterectomy with bilateral adnexectomy, total supracolic omentectomy, appendectomy, pelvic and/or para-aortic lymphadenectomy and multiple biopsies of macroscopically unchanged peritoneum were done.

Postoperatively, histopathological findings (HP) of removed tumours were analysed in order to establish a definitive diagnosis and staging of disease. From operating protocols, and HP reports, the extent of the surgery and the existence and size of possible residual tumour was determined. Based on the size of residual tumour tissue, patients were divided into 2 groups: patients with the largest diameters of residual tumour < $2 \mathrm{~cm}$ - complete and optimal cytoreduction, and patients with the largest diameters of residual tumour $\geq 2 \mathrm{~cm}$ - suboptimal cytoreduction. Postoperative chemotherapy was determined based on these data.

The survival rate (of 1, 3 and 5 years) was determined and all the factors that affect the survival rate were analysed for the patients who had been operated from one to five years before. Survival data were obtained in personal contact with patients (interview by telephone) or families of deceased patients, then from registry offices, municipality of residence of the patient and the Statistical Office of Bosnia and Herzegovina. 
Data was compared with Chi-squared test, using IMB SPSS version 16.0 statistical software. Statistical significance was set up at $\mathrm{p}<0.05$.

\section{Results}

The study included 59 patients with malignant epithelial ovarian tumour of stage III and stage IV (FIGO III and IV) who were primarily radically operated in the three-year time period. There were a total of 75 patients with epithelial ovarian tumours who were treated in the Clinic in that time period, but this study only included 59 (79 $\%)$ patients who were primarily operated. In 16 patients (21\%) only a biopsy was performed, eiTable 1: Clinical and pathological features of patients

\begin{tabular}{|c|c|c|c|}
\hline Parameters & Values & $\mathbf{N}$ & $\%$ \\
\hline \multirow{3}{*}{ Year of starting treatment } & 2008 & 17 & 128.8 \\
\hline & 2009 & 23 & 39.0 \\
\hline & 2010 & 19 & 32.2 \\
\hline \multirow{2}{*}{ Age groups } & $<65$ years & 43 & 72.9 \\
\hline & $\geq 65$ years & 16 & 27.1 \\
\hline \multirow{2}{*}{ Family history } & Negative & 53 & 89.8 \\
\hline & Positive & 6 & 10.2 \\
\hline \multirow{2}{*}{ Chronic diseases } & No & 38 & 64.4 \\
\hline & Yes & 21 & 35.6 \\
\hline \multirow{2}{*}{ Body Mass Index BMI (kg/m²) } & $\geq 25$ & 28 & 47.5 \\
\hline & $<25$ & 31 & 52.5 \\
\hline \multirow{3}{*}{ Ascites } & No & 18 & 31.6 \\
\hline & Yes & 39 & 68.4 \\
\hline & Missing & 2 & \\
\hline \multirow{2}{*}{ Tumour marker CA-125 (U/dL) } & $<500$ & 37 & 62.7 \\
\hline & $\geq 500$ & 22 & 37.3 \\
\hline \multirow{3}{*}{ Pathological diagnosis } & Serous & 39 & 66.1 \\
\hline & Mucinous & 7 & 11.9 \\
\hline & Other & 13 & 22.0 \\
\hline \multirow{5}{*}{ FIGO stage } & $3 a$ & 29 & 49.2 \\
\hline & $3 b$ & 6 & 10.2 \\
\hline & $3 c$ & 14 & 23.7 \\
\hline & $4 a$ & 7 & 11.9 \\
\hline & $4 b$ & 3 & 5.1 \\
\hline \multirow{3}{*}{ Chemotherapy } & No & 8 & 13.8 \\
\hline & Yes & 50 & 86.2 \\
\hline & Missing & 1 & \\
\hline \multirow{3}{*}{ Number of months of survival } & $<12$ & 10 & 16.9 \\
\hline & $12-36$ & 23 & 39.0 \\
\hline & $>36$ & 26 & 44.1 \\
\hline \multirow{3}{*}{ Alive October 2015} & Yes & 22 & 37.9 \\
\hline & No & 36 & 62.1 \\
\hline & Missing & 1 & 59.0 \\
\hline Patients & Total & 59 & 100.0 \\
\hline
\end{tabular}

ther by laparotomy or laparoscopy, and they were directed to neoadjuvant chemotherapy, and they were not included in this study. Table 1 shows the clinical and pathological features of patients, while Table 2 shows mean values and dispersion measures for continuous numerical variables.

Table 2: Mean values and dispersion measures of clinical features

\begin{tabular}{lcccc}
\hline Parameter & $\begin{array}{c}\text { Age } \\
\text { (Years) }\end{array}$ & $\begin{array}{c}\text { Body Mass } \\
\text { Index - BMI } \\
\text { (kg/m) }\end{array}$ & $\begin{array}{c}\text { Tumour marker } \\
\text { CA-125 (U/dL) }\end{array}$ & $\begin{array}{c}\text { Months of } \\
\text { survival }\end{array}$ \\
\hline Mean & 56.03 & 25.55 & 563.66 & 39.90 \\
\hline Median & 53.00 & 25.40 & 230.00 & 26.00 \\
\hline Mode & 51 & 24.10 & 85.00 & 13.00 \\
\hline Std. deviation & 12.72 & 3.20 & 826.56 & 29.92 \\
\hline Minimum & 29 & 19.60 & 10.00 & 0 \\
\hline Maximum & 86 & 35.40 & 4200 & 91 \\
\hline
\end{tabular}

Most of patients $(n=43)$ were $\geq 65$ years $(72.9$ $\%$ ), and most of patients did not have a history of gynaecological and breast malignancies (89.8 $\%$ ). Median age was $53 \pm 17.7$ years. Most patients (38), had no chronic diseases (64.4\%) and 31 of them had a body mass index (BMI) $\geq 25(52.5 \%)$. The median BMI was $25.4 \pm 3.1 \mathrm{~kg} / \mathrm{m}^{2}$.

Thirty-nine patients (66.1\%) had ascites and 36 of them had tumour marker values CA-125 $\geq$ $500 \mathrm{U} / \mathrm{dL}$ (62 \%). Tumour marker below 500 have been reported among the 17 patients who survived less than 3 years, which makes $51.5 \%$ of all patients who survived less than 3 years. Tumour markers below 500 have been reported among the 20 patients who survived more than 3 years, which makes $76.9 \%$ of all patients who survived over three years. The difference between these percentages (ratio) was statistically significant $(\mathrm{t}=2.004, \mathrm{p}=0.050)$. Thus, statistic shows that there are significantly more patients with tumour markers below 500 among the patients who survived 3 years and more, than among the patients who survived less than 3 years.

Optimal cytoreduction was performed in 21 patients $(35.5 \%)$ while 38 patients $(64.4 \%)$ were sub-optimally operated. The most common HP stage was serous type (66.1\%), while 29 patients (49.2 \%) had the most common FIGO stage 3a. Fifty patients $(84.7 \%)$ received postoperative chemotherapy.

In the first postoperative year 10 patients (16.9\%) died. In the period from 12 months to 36 months 23 patients (39\%) died, and other 26 patients 
died in the period after 36 months (44.1\%). Table 3 shows the number of the surviving patients after one, three and five years.

Table 3: The number of the surviving patients after one, three and five years

\begin{tabular}{lcc}
\hline Number of years of survival & N & $\%$ \\
\hline Up to 1 year (up to 12 months) & 50 & 84.70 \\
\hline Up to 3 years (36 months) & 26 & 44.10 \\
\hline Over 5 years (over 60 months) & 21 & 35.60 \\
\hline
\end{tabular}

In this research, 50 patients (84.7 \%) survived for one year, 26 patients (44.1\%) survived for three years, 21 patients survived for five years (37.3\%). Median survival was $26 \pm 29.9$ months (Table 2). Table 4 mostly show nominal variables and their correlation with the number of months of survival, which was tested using Chi-square tests, whose results are reported in Table 4 .

Table 4: Variables and their correlation with the number of months of survival (Chi-squared test)

\begin{tabular}{lrrrr}
\hline Variables in contingency table & N & $\mathbf{X}^{2}$ & df & p \\
\hline Age groups & 59 & 1.544 & 2 & 0.462 \\
\hline Family history & 59 & 1.961 & 2 & 0.375 \\
\hline Chronic diseases & 59 & 0.273 & 2 & 0.872 \\
\hline Body Mass Index - BMI $\left(\mathrm{kg} / \mathrm{m}^{2}\right)$ & 59 & 2.600 & 2 & 0.873 \\
\hline Ascites (Yes/No) & 57 & 2.976 & 2 & 0.226 \\
\hline Tumour markers & 59 & 4.456 & 2 & 0.108 \\
\hline Pathohistological diagnosis & 59 & 9.934 & 4 & 0.042 \\
\hline Cytoreduction & 59 & 22.949 & 2 & $<0.001$ \\
\hline FlGO stage & 59 & 42.791 & 8 & $<0.001$ \\
\hline Chemotherapy & 58 & 0.660 & 2 & 0.719 \\
\hline The year of the start of treatment & 59 & 6.979 & 4 & 0.137 \\
\hline
\end{tabular}

Red colour: statistical significance;

Statistically significant relationship was found between HP diagnosis and months of survival (classified in three groups). Interpretation of the association is the following: in patients with serous histologic type of diagnosis survival was the longest (54\% of patients survive over 3 years with this diagnosis). In patients with mucinous histologic type survival is the shortest, since $42 \%$ of them survived up to a year. Statistically significant association ( $p<0.001)$ was found between the level of cytoreduction and the number of months of survival. Significant correlation was found between FIGO stage and the number of months of survival $(\mathrm{p}<0.01)$.

\section{Discussion}

This research included 59 patients with malignant epithelial ovarian tumour of stages III and IV (FIGO III and IV) which were primarily radically operated in the three-year time period, in which there were a total of 75 patients with epithelial ovarian tumours who were treated in the Clinic. As is noted, this research included only the patients who were primarily operated and that is 59 patients (79\%). In 16 patients ( $21 \%$ ), only a biopsy was done, either by laparotomy or laparoscopy, and they were directed to neoadjuvant chemotherapy, and were excluded from this study. One of the reasons for exclusion of these patients was that researchers were unable to track and identify women treated with neoadjuvant chemotherapy before surgery because of the absence of data during the entire period of the study.

In 2016, Dahm-Kähler and colleagues from Sweden have posted a multicentre study, similar to this, in which they had $81 \%$ primarily operated, optimum cytoreduction in $37 \%$ to $49 \%$ of patients and the relative rate of the three-year survival ranged between $44 \%$ and $65 \% \cdot{ }^{15}$ In this study $85 \%$ of patients survived for one year after operation, $44 \%$ of patients survived for three years, and a five-year survival was $35.5 \%$. Median survival for the 59 patients followed was 26.25 months, which showed that the results of this study are similar to presented results.

This study examined the clinical pathological characteristics of tumour and survival of patients with advanced stage of epithelial ovarian cancer. Median age was 53 years, which is significantly lower than in other similar studies. In the research of Mueller et al median age was 62 years, while in the study Fotopouloua and associates, median age was $63 .{ }^{16,17}$ The difference and much earlier occurrence of advanced ovarian cancer in presented population is disturbing. Some studies show the impact of age on survival, which was not confirmed in this study. ${ }^{24}$

The results presented also identified the three most important factors affecting the survival of patients: HP type of tumour, tumour FIGO stage and the level of cytoreduction. Two independent prognostic factors, FIGO stage and histological type of tumour, have shown a great impact on survival. The most common histological type was 
serous epithelial ovarian cancer, which was also shown as the best prognostic factor with longer survival compared to other histological types. Also, nearly half of the patients were with FIGO stage IIIa, where the results of survival were better compared to other stages. These results are correlated with the results of other authors. ${ }^{18-20}$

Results also showed the importance of optimal cytoreduction and a great significance of residual tumour $<2 \mathrm{~cm}$ on the survival of patients with stage III and IV resectable ovarian cancer. Size of residual tumour after primary surgery is one of the most important prognostic factors according to most studies. ${ }^{21-23}$ Results clearly demonstrate the importance of surgical intervention and optimal cytoreduction on survival of our patients, and they are in correlation with other studies and in particular with study of Mette Ørsk and associates, where they concluded that the most important predictors of mortality within one year after surgery are residual tumour tissue $>2 \mathrm{~cm}(0-180$ days after surgery) and advanced FIGO stage of the disease. ${ }^{24}$ However, optimal cytoreduction was performed in only $35 \%$ of patients who had a significantly longer survival compared to patients treated with suboptimal operation, which showed the prognostic importance of optimal cytoreduction in this study as well.

This study has certain limitations, lack of information on smoking, alcoholism or use of drugs to stimulate ovulation and their impact on survival. Then, some treated patients were not acceptable for evaluation. Also, data on possible reoperations and data on neoadjuvant chemotherapy were not available. And finally, even if the exact time of death of the deceased patients was available, the information about the exact cause of death of patients was not, so, these data may have influenced the results of our research.

\section{Conclusion}

According to the results of this study, two important independent prognostic factors were found; the benefit of optimal cytoreduction $(<2$ $\mathrm{cm}$ of residual disease) that had the greatest prognostic value on survival and pathohistological type of tumour (serous histological type proved to be the most favourable). FIGO stage of the disease and the value of CA-125 markers were inversely correlated with the survival of patients. According to this results, patient survival was not significantly associated with age, family history of gynaecological malignancies and breast malignancies, comorbidities, or with the values of the BMI.

\section{Conflict of interest}

None.

\section{Acknowledgements}

None.

\section{References}

1. Jemal A, Bray F, Center MM, Ferlay J, Ward E, Forman D. Global cancer statistics. CA Cancer J Clin 2011 MarApr;61(2):69-90.

2. Jemal A, Siegel R, Ward E, Hao Y, Xu J, Thun MJ. Cancer statistics, 2009. CA Cancer J Clin 2009;59(4):225-49.

3. Dotlic J, Terzic M, Likic I, Atanacković J, Ladjević N. Evaluation of adnexal masses: correlation of clinical stage, ultrasound andhystopathological findings. Vojnosanit Pregl 2011;68:861-6.

4. Terzic M, Dotlic J, Likic I, Ladjevic N, Brndusic N, Mihailovic T, et al. Predictive factors of malignancy in patients with adnexal masses. Eur J Gynaec Oncol 2013;34:65-9.

5. Gazibara T, Filipović A, Kesić V, Kisiĉ-Tepavcević D, Pekmezović T. Risk factors for epithelial ovarian cancer in the female population of Belgrade, Serbia: a case-control study. Vojnosanit Pregl 2013;70:1097-102.

6. Molina R, Escudero JM, Augé JM, Filella X, Foj L, Torné A, et al. HE4 a novel tumour marker for ovarian cancer: comparison with CA 125 and ROMA algorithm in patients with gynaecological diseases. Tumour Biol 2011;32:1087-95.

7. Alleti G, Dowdy SC, Gostout BS, Jones MB, Stanhope CR, Wilson TO, et al. Aggressive surgical effort and improved survival in advanced-stage ovarian cancer. Obstet Gyneacol 2006,107:77-85.

8. Fotopoulou C, Savvatis K, Kosian P, Braicu IE, Papanikolaou G, Pietzner K, Schmidt SC, Sehouli J. Quaternary cytoreductive surgery in ovarian cancer: does surgical effort still matter? Br J Cancer 2013 Jan 15;108(1):32-8.

9. Bachmann R, Rothmund R, Krämer B, Brucker SY, Königsrainer A, Königsrainer I, et al. The prognostic role of optimal cytoreduction in advanced, bowel infiltrating ovarian cancer. J Invest Surg 2015 Jun;28(3):160-6.

10. Elstrand MB, Sandstad B, Oksefjell H, Davidson B, Tropé 
CG. Prognostic significance of residual tumor in patients with epithelial ovarian carcinoma stage IV in a 20 year perspective. Acta Obstet Gynecol Scand 2012;91:308-17.

11. Vergote I, Trope CG, Amant F, Kristensen GB, Ehlen T, Johnson $\mathrm{N}$, et al. Neoadjuvant chemotherapy or primary surgery in stage IIIC or IV ovarian cancer. N Engl J Med 2010;363:943-53.

12. Grann AF, Nørgaard M, Blaakær J, Søgaard-Andersen E, Jacobsen JB. Survival of patients with ovarian cancer in central and northern Denmark 1998-2009. Clin Epidemiol 2011;3 (Suppl 1):59-64.

13. Chi DS, Eisenhauer EL, Land J, Huh J, Haddad L, Abu-Rustum NR, et al. What is the optimal goal of primary cytoreductive surgery for bulky stage IIIC epithelial ovarian carcinoma(EOC)? Gynecol Oncol 2006;103:559-64.

14. Rutten MJ, Leeflang MM, Kenter GG, Mol BW, Buist M. Laparoscopy for diagnosing resectability of disease in patients with advanced ovarian cancer. Cochrane Database Syst Rev 2014 Feb 21;2014(2):CD009786. doi: 10.1002/14651858.CD009786.pub2.

15. Dahm-Kähler P, Palmqvist C, Staf C, Holmberg E, Johannesson L. Centralized primary care of advanced ovarian cancer improves complete cytoreduction and survival - A population-based cohort study. Gynecol Oncol 2016 Aug;142(2):211-6.

16. Mueller JJ, Zhou QC, Iasonos A, O'Cearbhaill RE, Alvi FA, El Haraki A, et al. Neoadjuvant chemotherapy and primary debulking surgery utilization for advanced-stage ovarian cancer at a comprehensive cancer center. Gynecol Oncol 2016 Mar;140(3):436-42.
17. Fotopoulou C, Jones BP, Savvatis K, Campbell J, Kyrgiou M, Farthing A, et al. Maximal effort cytoreductive surgery for disseminated ovarian cancer in a UK setting: challenges and possibilities. Arch Gynecol Obstet 2016 Sep;294(3):607-14.

18. Brun JL, Feyler A, Chêne G, Saurel J, Brun G, Hocké C. Longterm results and prognostic factors in patients with epithelial ovarian cancer. Gynecol Oncol 2000 Jul;78(1):21-7.

19. Cress RD, Chen YS, Morris CR, Petersen M, Leiserowitz GS, Characteristics of long-term survivors of epithelial ovarian cancer. Obstet Gynecol 2015 Sep;126(3):491-7.

20. Malkasian GD Jr, Decker DG, Webb MJ. Histology of epithelial tumors of the ovary: clinical usefulness and prognostic significance of the histologic classification and grading. Semin Oncol 1975 Sep;2(3):191-201.

21. Hoskins WJ. Epithelial ovarian carcinoma: principles of primary surgery. Gynecol Oncol 1994 Dec;55(3 Pt 2):S916. doi: 10.1006/gyno.1994.1346.

22. Bookman MA. Optimal primary therapy of ovarian cancer. Ann Oncol 2016 Apr;27 Suppl 1:i58-i62. doi: 10.1093/annonc/mdw088.

23. Elattar A, Bryant A, Winter-Roach BA, Hatem M, Naik R. Optimal primary surgical treatment for advanced epithelial ovarian cancer. Cochrane Database Syst Rev 2011 Aug 10;2011(8):CD007565. doi: 10.1002/14651858. CD007565.pub2.

24. Ørskov M, Iachina $M$, Guldberg $R$, Mogensen 0 , Mertz Nørgård B. Predictors of mortality within 1 year after primary ovarian cancer surgery: a nationwide cohort study. BMJ Open 2016 Apr 21;6(4):e010123. doi: 10.1136/bmjopen-2015-010123. 